\title{
Catalytic Dealkylative Synthesis of Cyclic Carbamates and Ureas via Hydrogen Atom Transfer and Radical-Polar Crossover
}

\author{
Takuya Nagai, Nao Mimata, Yoshihiro Terada, Chikayoshi Sebe, and Hiroki Shigehisa* \\ Faculty of Pharmacy, Musashino University \\ 1-1-20 Shinmachi Nishitokyo-shi, Tokyo 202-8585, Japan
}

KEYWORDS. Hydrogen atom transfer, radical-polar crossover, cyclic carbamates, cyclic ureas, cyclic phosphoramidate

\begin{abstract}
Guided by the transition metal hydrogen atom transfer and radical-polar crossover concept, we developed a catalytic, Markovnikov-selective, functional-group tolerant, and scalable synthesis of cyclic carbamates, which are found in the structures of many bioactive compounds. This method not only provides common oxazolidinones but also six-toeight-membered ring products. The reaction proceeds through the intramolecular displacement of an alkylcobalt(IV) intermediate and dealkylation by 2,4,6-collidine; the activation energies of these steps were calculated by DFT. Cyclic ureas and cyclic phosphoramidates were also synthesized under the same reaction conditions.
\end{abstract}

Much effort has been devoted in modern synthetic organic chemistry to the development of diverse methods for hydrofunctionalizing alkenes through transition-metal hydrogen-atom-transfer (TM-HAT) processes. ${ }^{1}$ A transition metal hydride generated in situ from a catalyst and a hydrogen source reacts with the alkene unit to chemoselectively generate a carbon-centered radical that then becomes involved in diverse transformations (Scheme IA). ${ }^{2}$ Recently, this mechanism has been shown to operate in conjunction with other transition metal catalysis mechanisms, thereby expanding the scope of the transformation. ${ }^{3}$

Our group has independently shown that the addition of an $\mathrm{N}$-fluorocollidinium salt to a commonly used cobaltSchiff base catalyst and a silane facilitates radical-polar crossover (RPC) to generating a cationic alkylcobalt(IV) intermediate. To date, we have disclosed that oxygen-, 4 nitrogen-, ${ }^{5}$ carbon- ${ }^{6}$ and sulfur ${ }^{7}$ nucleophiles react with these cationic species in TM-HAT chemistry. Among them, the formation of a lactone from an alkenyl ester is a profound example for us (Scheme 1B). ${ }^{\text {a }}$ In the light of related reports, ${ }^{2 q, 2 r, 7-8}$ it is plausible that the $\mathrm{sp}^{2}$-oxygen atom of the carbonyl group attacks the reactive cationic carbon of the alkylcobalt(IV) intermediate to release a cobalt(II) complex, after which removal of the methyl group by 2,4,6-collidine led to the lactone. Indeed, we computed the activation energies for the steps involving TS-a and TS-b to be only 11.0 and $14.1 \mathrm{kcal} / \mathrm{mol}$, which suggests that these two steps are possible. With the aim of expanding the substrate scope, the promising reactivity of the TM-HAT/RPC mechanism prompted us to design further cyclization reactions that involve poorly nucleophilic species.
Herein, we report the dealkylative cyclizations of alkenyl carbamates and alkenyl isoureas to afford cyclic carbamates and cyclic ureas, respectively (Scheme 1C). Cyclic carbamates and ureas are important structural motifs found in pharmaceuticals and bioactive agents, such as linezolid (antibiotic active against VRE and MRSA), ${ }^{9}$ efavirenz (anti-HIV drug), ${ }^{10}$ biotin (cofactor), ${ }^{11}$ and aquiledine (natural product). ${ }^{12}$ This observation encouraged synthetic chemists to develop various preparative methods for cyclic carbamates ${ }^{13}$ and cyclic ureas. ${ }^{14}$ However, to the best of our knowledge, the substrate scope of most reactions is limited to only common five- and sixmembered rings, and examples of medium ring formation are rather rare. ${ }^{33 a, 149}$ On the other hand, the method described here provides five- to eight-membered ring compounds.

We commenced by determining an appropriate carbamate structure using previously developed reaction conditions: cobalt catalyst $\mathbf{C}_{1}, N$-fluoro-2,4,6-collidinium trifluoromethanesulfonate (3), and 1,1,3,3tetramethyldisiloxane in benzotrifluoride at room temperature (Scheme 2). Although the desired oxazolidinone 2 was obtained from all substrates $\mathbf{1 a}-\mathbf{1 c}$, we found that tert-butyl carbamate 1c gave the best results. It should be noted that the methyl ester gave a better yield than the corresponding tert-butyl ester in the previously reported dealkylative cyclization that affords lactones. ${ }^{4 a}$ We also observed coproducts 4 in $196 \%$ yield from 1c. Therefore, the deprotonation of the tert-butyl group by 2,4,6collidine occurs after cyclization of the alkylcobalt(IV) intermediate. The activation energies for the steps involving TS-c and TS-d were calculated to be only 12.6 and 7.2 $\mathrm{kcal} / \mathrm{mol}$ (without the OMe group to reduce calculational costs), 
Scheme 1. TM-HAT and RPC mechanism

(A) TM-HAT catalyzed reaction

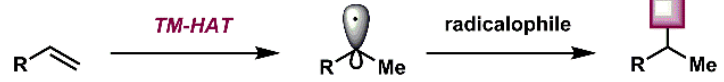

(B) Cyclization of esters to afford lactones via TM-HAT/RPC and DFT calculations for transition states of displacement and dealkylation ${ }^{a}$
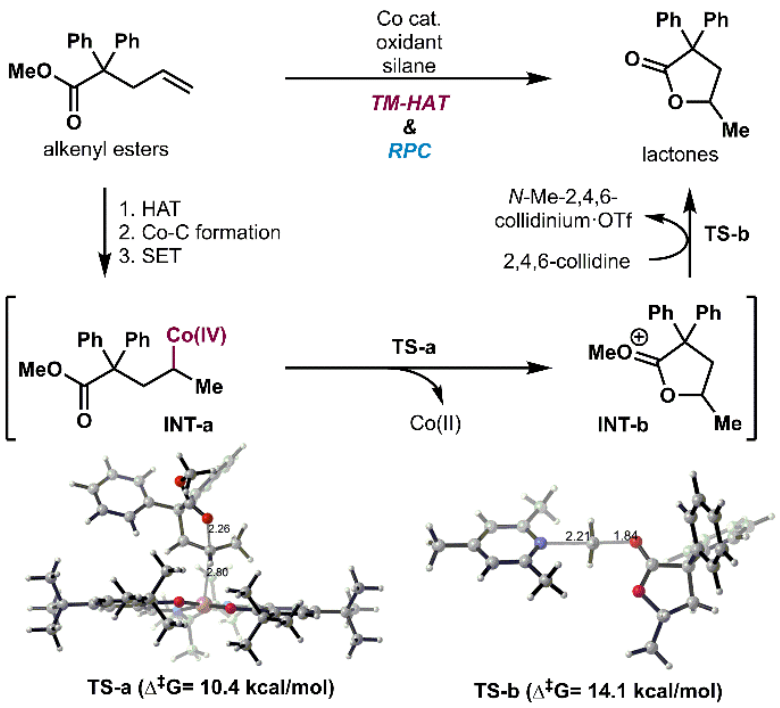

UBP86D3/6-311+G(d,p)/SMD( $\left.\mathrm{CF}_{3} \mathrm{Ph}\right) / / \mathrm{UB} 3 \mathrm{LYP} / 6-31 \mathrm{G}(\mathrm{d})$

Scheme 2. Initial attempt of oxazolidine synthesis ${ }^{\mathrm{a}}$<smiles>C=CCN(C(=O)O)c1ccc(OC)cc1</smiles>

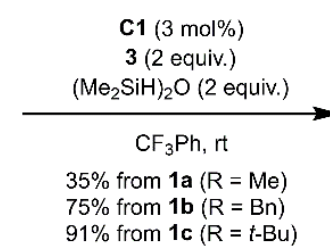

1a-1c<smiles>[AlH]C1CCCC1</smiles>
2. Co-C formation 3. SET
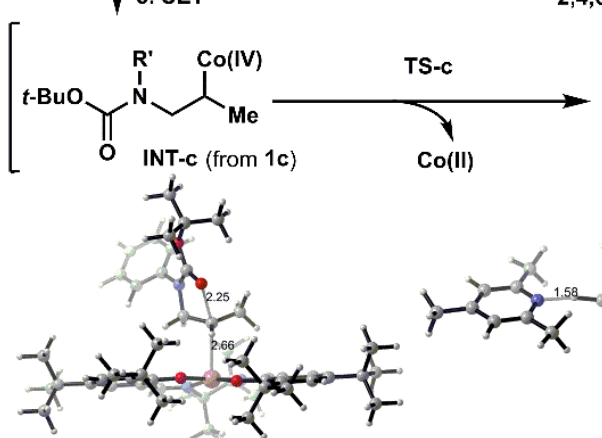

TS-c $\left(\Delta^{\ddagger} \mathrm{G}=12.6 \mathrm{kcal} / \mathrm{mol}\right)$ UBP86D3/6-311+G(d,p)/SMD(CF ${ }_{3}$ Ph)//UB3LYP/6-31G(d)
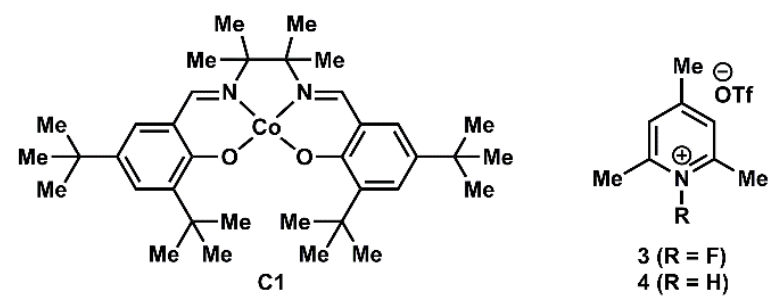

The reactions of $\mathbf{1 a}-\mathbf{1 c}(\mathbf{0 . 2 0} \mathrm{mmol})$ were performed in the presence of $\mathrm{Cl}_{\mathbf{1}}(3 \mathrm{~mol} \%), 3$ (2.0 equiv.), 1,1,3,3-
(C) Cyclization to afford cyclic carbamates \& ureas via TM-HAT/RPC and biologically active compounds and natural product (This Work)

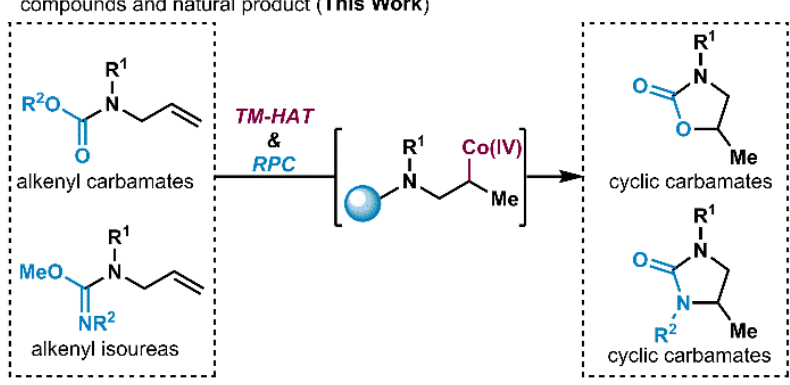

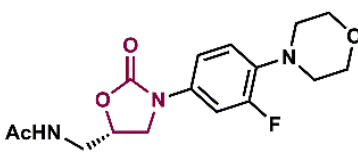

Linezolid

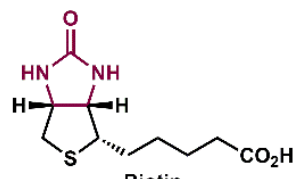

Biotin

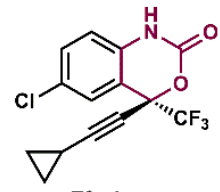

Efavirenz<smiles>O=C1NCCCC(c2c(O)cc3c(c2O)C(=O)C[C@@H](c2ccccc2)O3)N1</smiles>

tetramethyldisiloxane (2.0 equiv.) in benzotrifluoride (2.0 $\mathrm{mL}$ ) at room temperature for $18 \mathrm{~h}$ under argon. Isolated yields are shown. DFT calculations were performed for the synthesis of $\mathbf{5}$ to reduce calculational costs.

which suggests that the mechanism shown in Scheme 2 is feasible.

Encouraged by this result, we next examined the alkenyl carbamate scope for the formation of oxazolidinones (Table 1). Starting materials bearing hydrogen (i.e., 5) or a methyl group (i.e., 6) in the $p$-position of the aniline unit gave good yields of the desired products. On the other hand, the introduction of electron-withdrawing chloro, fluoro, and trifluoromethyl groups (7-9) led to significantly lower yields and the recovery of the alkenyl tert-butyl carbamate. Fortunately, we solved this problem by replacing the carbamate unit with a methyl group. Clearly, these results contrast with those from the reaction that produces $\mathbf{2}$ with the electron-donating methoxy group.

These aryl substituents would affect the rate of the intramolecular nucleophilic displacement and subsequent dealkylation, although their exact roles are not immediately clear. We also examined the functional group tolerance of this reaction using substrate 10 bearing a methylthio group, acid-sensitive acetal 11, and fluoride-sensitive silyl ether 12. The alkenyl tert-butylcarbamate bearing a disubstituted alkene, $p$-methoxybenzylamine, or $N$-tosyltryptamine cyclized to afford the desired products $13-15$. Moreover, amantadine derivative $\mathbf{1 6}$ was synthesized from the corresponding methyl carbamate on the 5 -mmol scale. The corresponding tert-butyl carbamate was not as efficiently synthesized as the methyl carbamate (See SI). 
We found that this method was able to form rings other than six-membered. Various cyclic carbamates 17-19 were prepared using the same reaction conditions from tertbutyl carbamates bearing $p$-methoxyaniline units (Table 2). To our great delight, these yields were improved by replacing the catalyst with $\mathbf{C} 2$, which was previously developed for the formation of medium rings by our group. $4^{\text {a }}$ Unfortunately, the yield of 19 was unsatisfactory. The methyl carbamate bearing the $p$-choroaniline unit and the tert-butyl carbamate bearing the $p$ methoxybenzylamine unit afforded the six-membered ring products $\mathbf{2 0}$ and $\mathbf{2 2}$ in good yields. However, we found that $\mathbf{2 1}$ and $\mathbf{2 3}$ were synthesized inefficiently using this method, even though $\mathbf{C}_{2}$ was used.

We next applied the same concept to the preparation of cyclic ureas from alkenyl isoureas. Alkenyl $\mathrm{N}$-tosyl-Omethylisoureas were synthesized from secondary amines in three steps (see $\mathrm{SI}$ ). We found that the $p$ toluenesulfonyl group was required to produce cyclic ureas. Irrespective of the electronic character of the substituent on the aniline unit, the yields of imidazolidinones 24-29 were generally good to excellent (Table 3). Alkenyl isoureas bearing a disubstitued alkene or a $p$ methoxybenzylamine unit were also cyclized efficiently to give 30 and 31. Six- and seven-membered cyclic ureas 32 and 33 were also prepared by this method in

Table 1. Scope of alkenyl carbamates affording 5 membered ring products

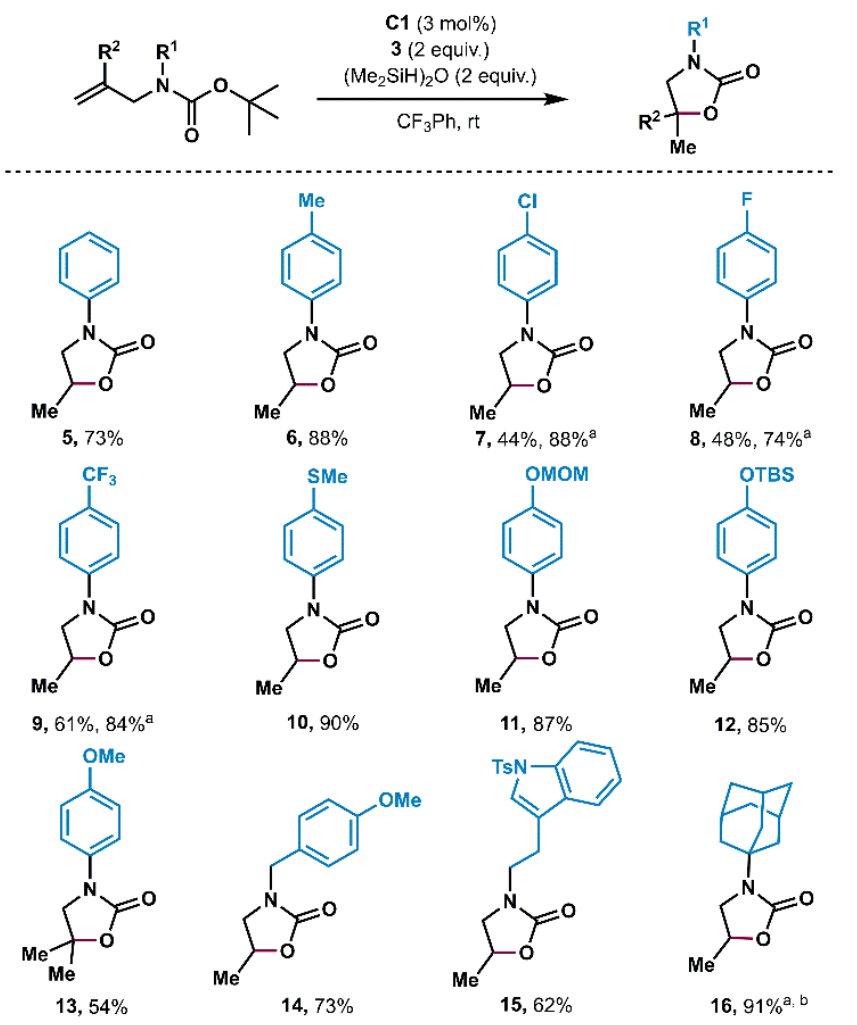

Conditions: alkenyl carbamate ( $0.2 \mathrm{mmol}), \mathbf{C l}_{1}(3 \mathrm{~mol} \%), 3$ (2 equiv.), 1,1,3,3-tetramethyldisiloxane (2 equiv.), benzotrifluoride $(2.0 \mathrm{~mL})$, room temperature, $18 \mathrm{~h}$. ${ }^{\mathrm{a}}$ Methyl carbamate was used instead. ${ }^{\mathrm{b}} 1.25 \mathrm{~g}(5 \mathrm{mmol})$ of starting material was used. good yields. A complex product mixture was formed and starting material was recovered in experiments aimed at forming eight-membered rings. We also investigated the cyclization of an alkenyl urea with the aim of potentially producing a cyclic urea. ${ }^{14 c}$ The cyclization of unpurified urea 35, synthesized from $N$-allylaniline (34) and $p$ toluenesulfonyl isocyanate in ethanol, afforded cyclic isourea 36 (without 25) in excellent yield from 34. Therefore, it is clear that the dealkylative cyclization approach is valuable from the perspective of $\mathrm{O} / \mathrm{N}$ selectivity.

With the aim of further extending synthetic utility, the $p$-toluenesulfonyl group in the product needed to be removable under mild conditions; however, we were unable to remove this group from $\mathbf{3 8}$ under common reaction conditions (Scheme 3). This observation prompted us to replace the $p$-toluenesulfonyl group with other groups, such as o-nitrobenzenesulfonyl and trifluoroacetyl. The yields of the cyclized products from 39 and 41 were acceptable and these transformations were scalable (1.0o g). Both protecting groups were removed to afford the same product 43 under mild conditions. In a preliminary attempt, the same reaction conditions were applied to the cyclization of alkenyl phosphoramidate 44 .

Table 2. Scope of alkenyl carbamates affording product of 6,7 , and 8 membered rings

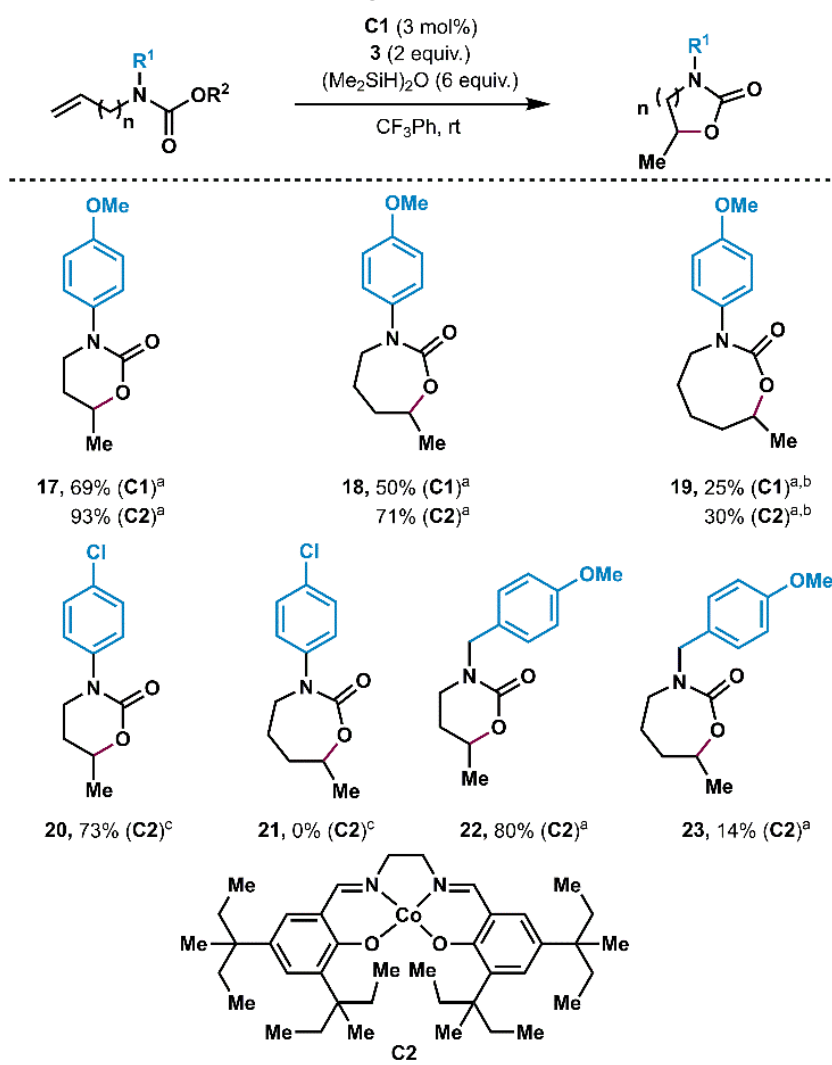

Conditions: alkenyl carbamate ( $0.2 \mathrm{mmol}), \mathbf{C}_{\mathbf{1}}$ (3 $\left.\mathrm{mol} \%\right), 3$ (2 equiv.), 1,1,3,3-tetramethyldisiloxane (2 equiv.), benzotrifluoride $(2.0 \mathrm{~mL})$, room temperature, $18 \mathrm{~h}$. ${ }^{\mathrm{a}}$ tert-Butyl carbamate was used instead. ${ }^{b} \mathbf{C}_{2}$ was used. 'Methyl carbamate was used. 
Although there is much room for improving both yield and selectivity, we obtained the cyclic phosphoramidate 45, together with a complex product mixture.

In summary, we developed a catalytic, Markovnikovselective, functional-group tolerant, scalable method for the synthesis of cyclic carbamates using a TM-HAT/RPC approach. This reaction proceeds through the cyclization of an alkylcobalt(IV) intermediate and dealkylation by 2,4,6-collidine, and the mechanism was determined to be reasonable by DFT calculations. Various cyclic carbamates were efficiently synthesized under mild condition. Cyclic ureas and a cyclic phosphoramidate were also synthesized in the same way. The HAT-initiated reaction developed here enables the construction of medium ring carbamates and ureas. We are currently investigating enantioselective versions of these dealkylative cyclizations using a chiral cobalt catalyst.

Table 3. Scope of alkenyl isoureas affording cyclic ureas. (a) Cyclization of alkenyl isoureas
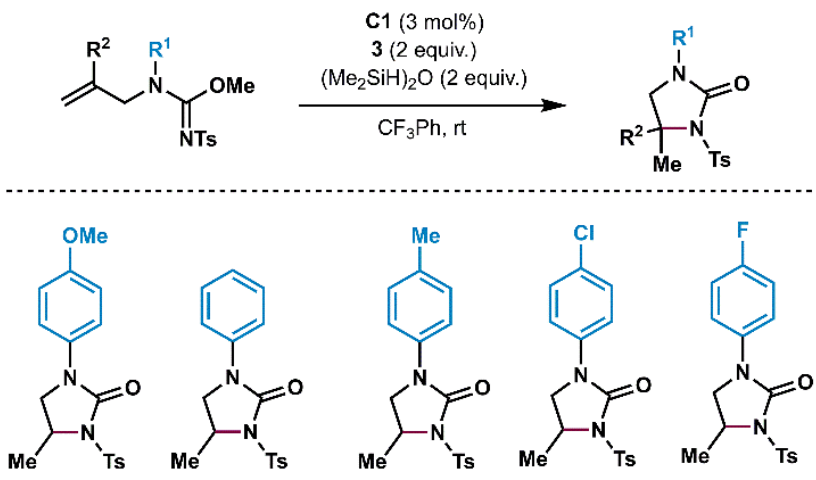

$24,80 \% \quad 25,76 \%$ 26, $95 \%$ $27,82 \%$ $28,74 \%$<smiles>CN1C(=O)N(c2ccc(C(F)(F)F)cc2)CC1[N+](=O)[O-]</smiles><smiles>COc1ccc(N2CC(C)(C)N(C)C2=O)cc1</smiles><smiles>C[C@@H]1CN(Cc2ccccc2)C(=O)N1C</smiles>

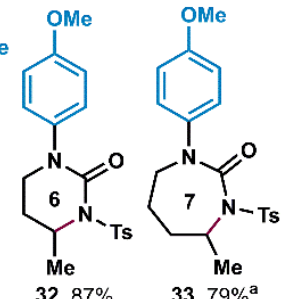

32, $87 \%$

$33,79 \%^{a}$
$30,75 \%$ $31,90 \%$ (b) Cyclization of alkenyl urea<smiles>C=CCNc1ccccc1</smiles>

34
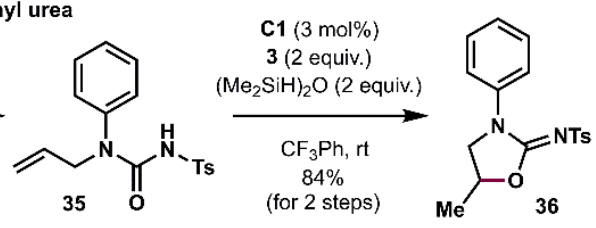

(a) Conditions: alkenyl carbamate (o.2 mmol), $\mathbf{C}_{\mathbf{1}}$ (3 mol\%), 3 (2 equiv.), 1,1,3,3-tetramethyldisiloxane (2 equiv.), benzotrifluoride $(2.0 \mathrm{~mL})$, room temperature, 18 hours. ${ }^{\mathrm{a}} \mathbf{C} \mathbf{2}$ was used instead.

\section{ASSOCIATED CONTENT}

Experimental procedures and analytical data $\left({ }^{1} \mathrm{H}\right.$ and ${ }^{33} \mathrm{C}$ NMR) for all new compounds. This material is available free of charge via the Internet at http://pubs.acs.org.

\section{AUTHOR INFORMATION}

\section{Corresponding Author}

*Email: cgehisa@musashino-u.ac.jp

\section{Funding Sources}

JSPS KAKENHI Grant number ${ }_{17} \mathrm{~K}_{15426}$

The Takeda Science Foundation

The research foundation for pharmaceutical sciences

\section{ACKNOWLEDGMENT}

We thank Prof. Kou Hiroya (Musashino University) for our liberal research environment. We thank Dr. Yasunori Toda (Shinshu University) for helpful advice on how to prepare cyclic phosphoramidate. We thank Dr. Ryo Takita (University of Tokyo) for helpful advice on how to find TS-d. We thank This work was supported by JSPS KAKENHI Grant number $17 \mathrm{~K} 15426$, the Takeda Science Foundation, and the Research Foundation for Pharmaceutical Sciences. Computational chemistry was carried out using the computer facilities at the Research Institute for Information Technology, Kyushu University.

Scheme 3. Additional experiment for cyclic urea synthesis

(a) Synthesis of protective group free cyclic urea
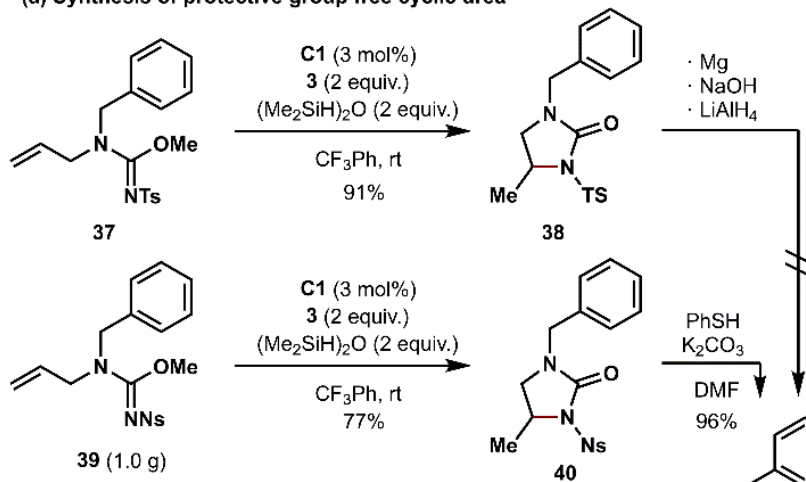

$39(1.0 \mathrm{~g})$
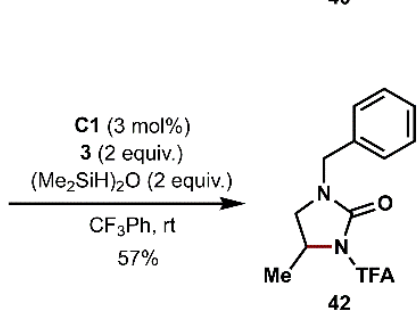



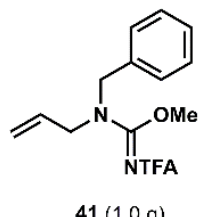

$57 \%$

42

(b) Cyclization of alkenyl phosphoramidate

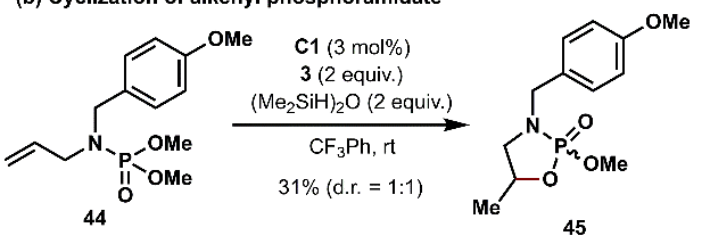

REFERENCES

(1) (a) Green, S. A.; Crossley, S. W. M.; Matos, J. L. M.; Vásquez-Céspedes, S.; Shevick, S. L.; Shenvi, R. A., The High Chemofidelity of Metal -Catalyzed Hydrogen Atom Transfer. Acc. Chem. Res2018 51, 26282640. (b) Crossley, S. W.; Obradors, C.; Martinez, R. M.; Shenvi, R. A., Mr, Fe-, and Co-Catalyzed Radical Hydrofunctionalizations of OlefinEhem. Rev2016 116, $8912-9000$. 
(2) (a) Dao, H. T.; Li, C.; Michaudel, Q.; Maxwell, B. D.; Baran, P. S., Hydromethylation of Unactivated Olefins.. Am. Chem. Soc. 2015 137, 8046-8049. (b) Lo, J. C.; Kim, D.; Pan, C. M.; Edwards, J. T.; Yabe, Y.; Gui, J.; Qin, T.; Gutierrez, S.; Giacoboni, J.; Smith, M. W.; Holland, P. L.; Baran, P. S., FGatalyzed GC Bond Construction from Olefins via Radicals.. Am. Chem. Soc. 2017, 139, 24842503. (c) Lo, J. C.; Yabe, Y.; Baran, P. S., A Practical and Catalytic Reductive Olefin Coupling. Am. Chem. Soc.2014 136, 13041307. (d) Lo, J. C.; Gui, J.; Yabe, Y.; Pan, C. M.; Baran, P. S., Functionalized Olefin Crossoupling to Construct Carboncarbon BondsNature2014, 516,343-348. (e) Gui, J.; Pan, C. M.; Jin, Y.; Qin, T.; Lo, J. C.; Lee, B. J.; Spergel, S. H.; Mertzman, M. E.; Pitts, W. J.; La Cruz, T. E.; Schmidt, M:; A Darvatkar, N.; Natarajan, S. R.; Baran, P. S., Practical Olefin Hydroamination with Nitroarenescience2015 348,886-891. (f) Barker, T. J.; Boger, D. L., $\mathrm{Fe}(\mathrm{III}) / \mathrm{NaBH}$-mediated free radical hydrofluorination of unactivated alkenes.Am. Chem. So2012 134, 1358813591. (g) Ishikawa, H.; Colby, D. A.; Seto, S.; Va, P.; Tam, A.; Kakei, H.; Rayl, T. J.; Hwang, I.; Boger, D. L., Total Synthesis of Vinblastine, Vincristine, Related Natural Products, and Key Structural Analogues. J. Am. Chem. Soc. 2009 131, 49044916. (h) Leggans, E. K.; Barker, T. J.; Duncan, K. K.; Boger, D. L., Iron(III)/NaBH-mediated Additions to Unactivated Alkenes: Synthesis of Novel 20Inblastine AnaloguesOrg. Lett. 2012 14, 14281431. (i) Gaspar, B.; Carreira, E. M., Cataytic hydrochlorination of unactivated olefins with packuenesulfonyl chloride.Angew. Chem. Int. EQ2008 47,57585760. (j) Gaspar, B.; Carreira, E. M., Cobalt Catalyzed Functionalization of Unactivated Alkenes: Regioselective Reductive GC Bond Form ing ReactionsJ. Am. Chem. Soz009 131,1321413215. (k) Waser, J.; Carreira, E. M., Convenient synthesis of alkylhydrazides by the cobaltcatalyzed hydrohydrazination reaction of olefins and azodicarboxylatesJ. Am. Chem. Soc2004, 126, 5676-5677. (l) Waser, J.; Gaspar, B.; Nambu, H.; Carreira, E. M., Hydrazines and Azides via the Metakatalyzed Hydrohydrazination and Hydroazidation of Olefins. J. Am. Chem. Soc. 2006 128, 11693 11712. (m) Waser, J.; Nambu, H.; Carreira, E. M., Cobalt Catalyzed Hydroazidation of Olefins: Convenient Access to Alkyl Azides. J. Am. Chem. Soc.2005 127, 82948295. (n) Ma, X.; Herzon, S. B., Non-classical Selectivities in the Reduction of Alkenes by Cobaltmediated Hydrogen Atom Transferhem. Sci. 2015 6, 62506255. (o) King, S. M.; Ma, X.; Herzon, S. B., A Method for the Selective Hydrogenation of Alkenyl Halides to Alkyl Halides. J. Am. Chem. Soe2014, 136,68846887. (p) Ma, X.; Herzon, S. B., Intermolecular Hydropyridylation of Unactivated Alkenes. J. Am. Chem. Soc. 2016 138, 87188721. (q) Touney, E. E.; Foy, N. J.; Pronin, S. V., Catalytic Radicafolar Crossover Reactions of Allylic Alcohols. Am. Chem. So2018 140,1698216987. () Discolo, C. A.; Touney, E. E.; Pronin, S. V., Catalytic Asymmetric RadicatPolar Crossover Hydroalkoxylation. J. Am. Chem. Soc2019 17527-17532. (s) Crossley, S. W. M.; Barabé, F.; Shenvi, R. A., Simple, Chemoselective, Catalytic Olefin Isomerization J. Am. Chem. So2014 136,1678816791. (t) Green, S. A.; Huffman, T. R.; McCourt, R. O.; van der Puyl, V.; Shenvi, R. A., Hydroalkylation of Olefins To Form Quaternary Carbons J. Am. Chem. So2019 141,77097714. (u) Iwasaki, K.; Wan, K. K.; Oppediano, A.; Crossley, S. W. M.; Shenvi, R. A., Simple, Chemoselective Hydrogenation with Thermodynamic Stereocontrol. Am. Chem. So2014, 136,13001303. (v) Matos, J. L. M.; Vasqueßespedes, S.; Gu, J.; Oguma, T.; Shenvi, R. A., Branch -Selective Addition of Unactivated Olefins into Imines and Aldehydes. J. Am. Chem. Soc. 2018 140, 16976 16981. (w) Obradors, C.; Martinez, R. M.; Shenvi, R. A., PhtPrO)SiH: An Exceptional Reductant for Met@atalyzed Hydrogen Atom Transfers/. Am. Chem. So2016, 138, 4962-4971. (x) Sun, H.L.; Yang, F.; Ye, W.-T.; Wang, J.J.; Zhu, R., Dual Cobalt and Photoredox Catalysis Enabled Intermolecular Oxidative
HydrofunctionalizationACS Cata/2020 49834989. (y) Wu, B.; Zhu, R., Radical Philicity Inversion in Coand Fe-Catalyzed HydrogenAtom-TransfefInitiated Cyclizations of Unsaturated Acylsilanes ACS Catal2020 10,510-515. (z) Zhou, X. L.; Yang, F.; Sun, H. L.; Yin, Y. N.; Ye, W. T.; Zhu, R., CobalıCatalyzed Intermolecular Hydrofunctionalization of Alkenes: ilence for a Bimetallic Pathway. J. Am. Chem. Soc.2019 141, 72507255. (aa) Shen, X.; Chen, X.; Chen, J.; Sun, Y.; Cheng, Z.; Lu, Z., Ligand-promoted cobalt-catalyzed radical hydroamination of alkenes.Nature Communication 2020 11, 783. (ab) Wang, Y. Y.; Bode, J. W., Olefin Amine (OLA) Reagents for the Synthesis of Bridged Bicyclic and Spirocyclic SaturateAk-Heterocycles by Catalytic Hydrogen Atom Transfer (HAT) Reactions. J. Am. Chem. Soc2019 141,97399745. (ac) Jiang, H.; Lai, W.; Chen, $\mathrm{H}$., Generation of Carbon Radical from Iron -Hydride/Alkene: ExchangeEnhanced Reactivity Selects the Reactive Spin State. ACS Catal.2019 9, 60806086. (ad) Shen, Y.; Qi, J.; Mao, Z.; Cui, S., Fe -Catalyzed Hydroalkylation of Olefins with para Quinone MethidesOrg. Lett.2016

(3) (a) Green, S. A.; Matos, J. L. M.; Yagi, A.; Shenvi, R. A., BranchSelective Hydroarylation: lodoarene -Olefin Cross Coupling. J. Am. Chem. Soc2016 138, 1277912782. (b) Shevick, S. L.;Obradors, C.; Shenvi, R. A., Mechanistic Interrogation of Co/Ni-Dual Catalyzed Hydroarylation.. Am. Chem. Soro18 140,1205612068.

(4) (a) Shigehisa, H.; Hayashi, M.; Ohkawa, H.; Suzuki, T.; Okayasu, H.; Mukai, M.; Yamazaki, A.; Kawai, R.; Kikuchi, H Satoh, Y.; Fukuyama, A.; Hiroya, K., Catalytic Synthesis of Saturated Oxygen Heterocycles by Hydrofunctionalization of Unactivated Olefins: Unprotected and Protected Strategies $m$. Chem. e Soc.2016 138,10597-10604. (b) Shigehisa, H.; Aoki, T.; Yamaguchi, S.; Shimizu, N.; Hiroya, K., Hydroalkoxylation of Unactivated Olefins with Carbon Radicals and Carbocation Species as Key IntermediatesJ. Am. Chem. So2013, 135,1030610309.

(5) Shigehisa, H.; Koseki, N.; Shimizu, N.; Fujisawa, M.; Niitsu, M.; Hiroya, K., Catalytic Hydroamination of Unactivated Olefins Using a Co Catalyst for Complex Molecule Synthesis. J. Am. Chem. Soc2014 136,1353413537.

(6) Shigehisa, H.; Ano, T.; Honma, H.; Ebisawa, K.; Hiroya, K., Co-Catalyzed Hydroarylation of Unactiated Olefins. Org. Lett. 2016 18,3622-3625.

(7) Date, S.; Hamasaki, K.; Sunagawa, K.; Koyama, H.; Sebe, C.; Hiroya, K.; Shigehisa, H., Catalytic Direct Cyclization of Alkenyl Thioester ACS Cata/2020 10,20392045.

(8) (a) Vol'pin, M. E.; Levitin, I. Y.; Sigan, A. L.; Halpern, J.; Tom, G. M., Reactivity of Organocobalt(IV) Chelate Complexes Toward Nucleophiles: Diversity of Mechanisms. Inorg. Chim. Acta1980 41,271-277. (b) Magnuson, R. H.; Halpern, J.; Levitin, I. Y.; Vol'pin, M. E., Stereochemistryof the Nucleophilic Cleavage of Cobaltcarbon Bonds in Organocobalt(IV) Compounds. Chem. Soc., Chem. Commun978 44-46. (c) Anderson, S. N.; Ballard, D. H.; Chrzastowski, J. Z.; Dodd, D.; Johnson, M. D., Inversion of Configuration in the NucleophilicDisplacement of Cobalt from Alkylcobalt(IV) Complexes and Its Relevance to the Halogenation of the Corresponding Alkylcobalt(III) Complexes. Chem. Soc., Chem. Comm\$972, 685686.

(9) Mukhtar, T. A.; Wright, G. D., Streptogramins, Oxazolidinones, and Other Inhibitors of Bacterial Protein Synthesis. Chem. Rev2005 105,529-542.

i, (10) Young, S. D.; Britcher, S. F.; Tran, L. O.; Payne, L. S.; Lumma, W. C.; Lyle, T. A.; Huff, J. R.; Anderson, P. S.; Olsen, D. B.; Carroll, S. S., L-743, 726 (DMP266): a novel, highly potent nonnucleoside inhibitor of the human immunodeficiency virus type 1 reverse transcriptasentimicrob. Agents ChemothA995, $39,2602-2605$.

(11) Cronan, J. E., Advances in synthesis of biotin and assembly of lipoic acid.Curr. Opin. Chem. BioR018 47,60-66. 
(12) Chen, S.-B.; Gao, G.-Y.; Leung, H.-W.; Yeung, H.-W.; Yang, J.-S.; Xiao, P.-G., Aquiledine and Isoaquiledine, Novel Flavonoid Alkaloids from Aquilegia ecalcaratal. Nat. Prod. 2001, 64, $85-$ 87.

(13) (a) Niemi, T.; PereaBuceta, J. E.; Fernández, I.; Hiltunen, O.-M.; Salo, V.; Rautiainen, S.; Räisänen, M. T.; Repo, T., A OnePot Synthesis of NAryl-2-Oxazolidinones and Cyclic Urethanes by the Lewis Base Catalyzed Fixation of Carbon Dioxide into Anilines and BromoalkanesChem. Eur. J2016 22, 10355 10359. (b) Jagtap, S. R.; Patil, Y. P.; Fujita, S. -I.; Ar ai, M.; Bhanage, B. M., Heterogeneous base catalyzed synthesis of 2 oxazolidinones/Zmidiazolidinones via transesterification of ethylene carbonate with faminoalcohols/1,2-diamines. Applied Catalysis A: GeneraR008 341,133-138. (c) Zhang, Y.; Zhang, Y.; Xie, S.; Yan, M.; Ramström, O., Lipase-catalyzed kinetic resolution of 3-phenyloxazolidin-2-one derivatives: Cascade O- and $\mathrm{N}$ alkoxycarbonylations. Catal. Commun. 2016 82, 11-15. (d) Zhang, Y.; Zhang, Y.; Ren, Y.; Ramström, O., Synthesis of chiral oxazolidinone derivatives through lipase-catalyzed kinetic resolution. J. Mol. Catal. B: Enzym. 2015 122, 29-34. (e) Toda, Y.; Gomyou, S.; Tanaka, S.; Komiyama, Y.; Kikuchi, A.; Suga, H., Tetraarylphosphonium Salt-Catalyzed Synthesis of Oxazolidinones from Isocyanates and Epoxides. Org. Lett. 2017, 19, 5786-5789. (f) Paddock, R. L.; Adhikari, D.; Lord, R. L.; Baik, M.-H.; Nguyen, S. T., [(Salcen)CrIII + Lewis base]-catalyzed synthesis of N-aryl-substituted oxazolidinones from epoxides and aryl isocyanates. Chem. Commun. 2014 50, 15187-15190. (g) Ishida, T.; Kobayashi, R.; Yamada, T., Novel Method of Tetramic Acid Synthesis: Silver-Catalyzed Carbon Dioxide Incorporation into Propargylic Amine and Intramolecular Rearrangement. Org. Lett.2014 16, 2430-2433. (h) Wang, P.; Qin, J.; Yuan, D.; Wang, Y.; Yao, Y., Synthesis of Oxazolidinones from Epoxides and Isocyanates Catalyzed by Rare-Earth-Metal Complexes. ChemCatChem 2015 7, 1145-1151. (i) Niemi, T.; Fernández, I.; Steadman, B.; Mannisto, J. K.; Repo, T., Carbon dioxide-based facile synthesis of cyclic carbamates from amino alcohols. Chem. Commun2018 54, 3166-3169. (j) Robles-Machín, R.; Adrio, J.; Carretero, J. C., Gold-Catalyzed Synthesis of Alkylidene 2Oxazolidinones and 1,3-Oxazin-2-ones. J. Org. Chem.2006, 71, 5023-5026. (k) Yousefi, R.; Struble, T. J.; Payne, J. L.; Vishe, M.; Schley, N. D.; Johnston, J. N., Catalytic, Enantioselective Synthesis of Cyclic Carbamates from Dialkyl Amines by CO2-Capture: Discovery, Development, and Mechanism. J. Am. Chem. Soc. 2019 141,618-625

(14) (a) Hinds, E. M.; Wolfe, J. P., A Cross-Metathesis/AzaMichael Reaction Strategy for the Synthesis of Cyclic and Bicyclic Ureas. J. Org. Chem.2018 83, 10668-10676. (b) Streuff, J.; Hövelmann, C. H.; Nieger, M.; Muñiz, K., Palladium(II)Catalyzed Intramolecular Diamination of Unfunctionalized Alkenes. J. Am. Chem. Soc2005 127, 14586-14587. (c) Rao, W.H.; Yin, X.-S.; Shi, B.-F., Catalyst-Controlled Amino- versus Oxy-Acetoxylation of Urea-Tethered Alkenes: Efficient Synthesis of Cyclic Ureas and Isoureas. Org. Lett.2015 17,3758-3761. (d) Wu, M.-S.; Fan, T.; Chen, S.-S.; Han, Z.-Y.; Gong, L.-Z., Pd(II)Catalyzed Asymmetric Oxidative 1,2-Diamination of Conjugated Dienes with Ureas. Org. Lett.2018 20,2485-2489. (e) Struble, T. J.; Lankswert, H. M.; Pink, M.; Johnston, J. N., Enantioselective Organocatalytic Amine-Isocyanate Capture-Cyclization: Regioselective Alkene Iodoamination for the Synthesis of Chiral Cyclic Ureas. ACS Cata/2018 8, 11926-11931. (f) Kondoh, A.; Kamata, Y.; Terada, M., Synthesis of Enantioenriched $\gamma$-Amino- $\alpha, \beta$ unsaturated Esters Utilizing Palladium-Catalyzed Rearrangement of Allylic Carbamates for Direct Application to Formal [3 + 2] Cycloaddition. Org. Lett. 2017, 19, 1682-1685. (g) Zhang, H.; Tian, P.; Ma, L.; Zhou, Y.; Jiang, C.; Lin, X.; Xiao, X., Remote Directed Isocyanation of Unactivated $\mathrm{C}(\mathrm{sp} 3)-\mathrm{H}$ Bonds: Forging
Seven-Membered Cyclic Ureas Enabled by Copper Catalysis. Org. Lett. 2020 22,997-1002. 
Insert Table of Contents artwork here

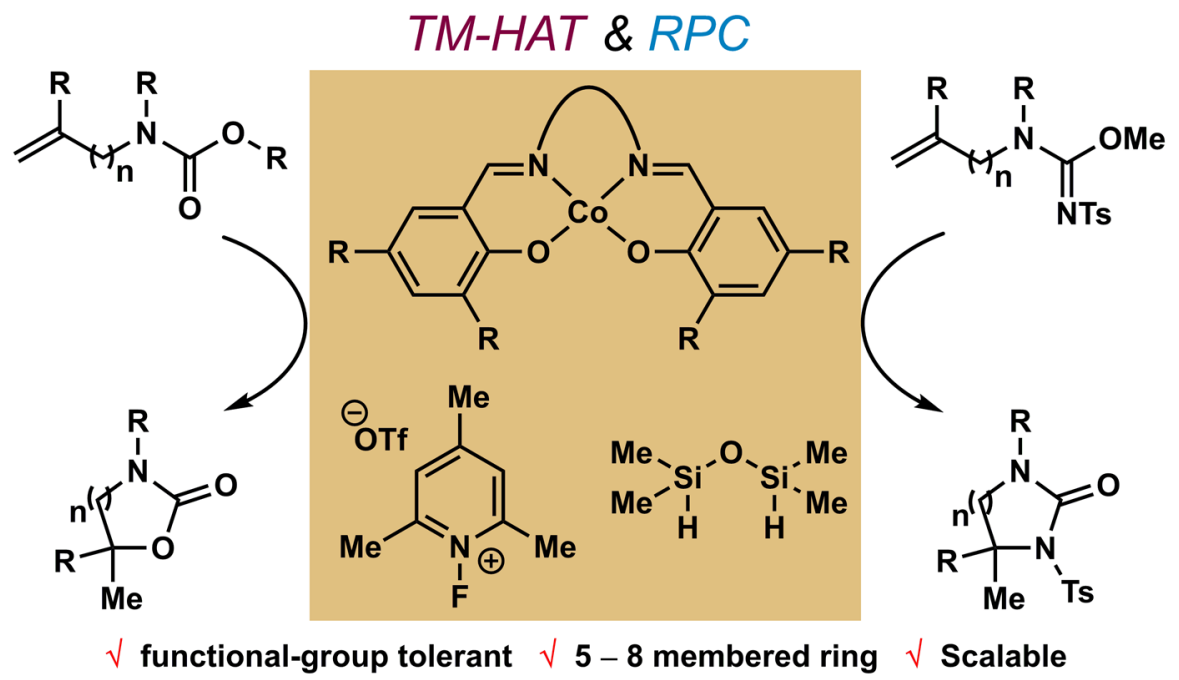

